\title{
Changes in the frequency of food intake among children and teenagers: monitoring in a reference service ${ }^{1}$
}

\author{
Larissa Soares Mariz ${ }^{2}$ \\ Carla Campos Muniz Medeiros ${ }^{3}$ \\ Caroline Evelin Nascimento Kluczynik Vieira ${ }^{4}$ \\ Bertha Cruz Enders ${ }^{5}$ \\ Alexsandro Silva Coura ${ }^{3}$
}

Purpose: to identify changes in the food intake patterns among overweight children and teenagers, treated at a reference medical centre. Method: the method used is that of a cohort study, between April 2010 and April 2011. A total of 109 children and teenagers, either obese or overweight, took part in the study. The population was divided into two subgroups depending on the permanence period (more than 6 months, and less than 6 months off the treatment). The chi-square test and logistic regression were carried out. Results: the group which had been longer off the treatment tended to consume more soft drinks, pasta and fried foods, and less fruit and vegetables. The group with less time showed an improvement, with a reduction of consumption of soft drinks and other goodies. There was confirmation of an increased risk for consumption of soft drinks, pasta and goodies in general, as also detachment from the treatment in adolescence. Conclusions: The group with a longer period of monitoring has had a positive change in food intake frequency. The main contribution made by this study is that of showing that multiprofissional treatment, including some nursing care, is efficient in progressively changing the food intake of children and adolescents who are overweight.

Descriptors: Obesity; Overweight; Continuity of Patient Care; Child; Adolescent; Nursing.

\footnotetext{
${ }^{1}$ Paper extracted from master's thesis "Fatores de risco cardiovascular e condições associadas ao seguimento de crianças e adolescentes obesos ou com sobrepeso em um centro de referência" presented to Universidade Estadual da Paraíba, Campina Grande, PB, Brazil.

${ }^{2}$ Doctoral student, Centro de Ciências da Saúde, Universidade Federal do Rio Grande do Norte, RN, Brazil. Professor, Universidade Estadual da Paraíba, Campina Grande, PB, Brazil.

${ }^{3} \mathrm{PhD}$, Professor, Departamento de Enfermagem, Universidade Estadual da Paraíba, Campina Grande, PB, Brazil.

${ }^{4}$ Master's student, Universidade Federal do Rio Grande do Norte, RN, Brazil.

${ }^{5}$ PhD, Full Professor, Centro de Ciências da Saúde, Universidade Federal do Rio Grande do Norte, RN, Brazil.
} 


\section{Introduction}

In Brazil, overweight and obesity are considered important nutritional deviations. The storage of body fat at school age tends to linger into adolescence, and has physiological and pathological effects on adulthood. For this reason, characteristics such as risk groups and possibilities of success of actions to be implemented mean that children and adolescents with excess weight are a target group for strategies aiming at prevention and control of overweight and related illnesses ${ }^{(1)}$.

The importance of the diet in the aetiology of obesity has been made evident through the growing number of epidemiological studies, where eating habits are one of the most important factors which can be changed. More and more, there is a move towards a search for food patterns that make one prone to gain body fat, so that public health policies can be implemented to tackle this problem(2).

The emphasis that the Brazilian Ministry for Health has placed on inadequate eating habits, acquired in childhood, is due to the fact that these can have an important influence on the development of chronic non-contagious diseases. However, the relationship between diet and illness is not always detected in the epidemiological studies, often due to the difficulties to accurately assess food ingestion (3).

In this regard, the World Health Organisation (WHO) forecasts that scientific research about food intake, taken together, may be more relevant than nutrients analysed on an individual basis. The WHO also suggests that the food intake recommendations for people should be based on foods rather than nutrients. The associations found must be simple, easy to interpret and able to be converted into knowledge that may, in turn, be transferred to acceptable standards of conduct at the level of public health(4).

The process of modification of eating habits is complex, even more thanks to the current lifestyle, and there is a need to draw up strategies together with the patient, so that he or she may be able to understand the need and the importance of addressing this problem. With this goal in mind, some years ago an Infant Obesity Centre (Centro de Obesidade Infantil - COI) was implemented in Campina Grande, State of Paraíba, Brazil; this unit is now a reference benchmark in the treatment of obesity in this city, where the person who has signed up to participate is seen to by a multidisciplinar team which seeks to change the habits of the individual and also of his or her family(5).
This comprises researchers and also health professionals such as nurses, endocrinologists, nutritionists, a psychologist, a social worker and a physical trainer. The capture of children and adolescents was made through a campaign publicising the COI at the Basic Health Units of the municipality, by the Secretariat for Health, after an initial survey(5).

To reach an appropriate number for the first survey and the foundation of the COI, use was made of a sample calculation which gave a total of 202 individuals aged between 2 and 18, either obese or overweight, and these would then be part of the multiprofissional monitoring process used by the COI.

The nurse on this team acts as a health promoter, and also provides prevention of the complications caused by obesity. It is important to stress that the treatment of obesity in childhood and youth does not only mean listing conduct patterns, but also the construction of healthy habits throughout life, as shown in the Manual for Monitoring of Growth and Human Development, of the Brazilian Ministry for Health ${ }^{(6)}$.

The instrument mentioned above says that, in Primary Care, the nurse has the responsibility of analysing the weight of the child and the adolescent according to the WHO growth curve. In the case of an ascendant result, above the $97^{\text {th }}$ percentile, the conduct shall be based on the confirmation of nutritional errors, suggesting a more appropriate eating style to the mother, according to the standards contained in the Manual itself, by means of a limited-calorie diet for children aged 4 and over, and also checking and encouragement of regular physical activity. Other responsibilities of the nurse are those of being aware of the normal development of the child and variations thereto, offering guidance to the family and also, in case of need, sending the patient on for diagnosis and intervention as soon as possible ${ }^{(6)}$.

The options of conventional treatment of overweight and obesity do not always lead to success. On the other hand, a programme of obesity treatment by a multiprofessional team, constantly monitoring, may contribute significantly to the reduction of adiposity among children and teenagers ${ }^{(7)}$. A study carried out with obese children and teenagers, in the state of Minas Gerais, suggests that treatment by a multidisciplinary team has shown itself to be more efficient as treatment for obesity when compared to treatment by only one professional, as this enables closer contact with the patient and his or her family and possibly a closer bond, thereby generating better results ${ }^{(8)}$. 
Therefore, in the light of the complexity of factors related to the treatment of children and teenagers with excess weight, in this study we have considered treatment as being a group of multidisciplinary activities, with priority being given to physical exercise, re-education of food habits, prevention and treatment of metabolic problems, psychological attention and special groups for re-education of eating habits.

Starting out from the assumption that multidisciplinary treatment and the duration of the monitoring period may change the eating habits of children and adolescents( ${ }^{(7-8)}$, it was sought to identify changes in the frequency of food intake by children and adolescents with excess weight, monitored by a reference service.

We also believe in the relevance of this study, as the issue of child obesity is part of the National Agenda of Health Research Priorities ${ }^{(9)}$; through the difficulties found by nurses responsible for the care provided to this population, in order to provide adequate assistance and in the light of the start of production of the nursing sector based on this approach; and also considering the possibility of making a contribution for the strengthening of public health policies aimed at the child, seeking to promote lifelong health. In addition, a change in the eating frequency of the subjects of this study, by means of multiprofessional treatment, are references for the establishment of new specialised services in order to bring down the obesity rates among children and teenagers, thus tackling what has become a global health problem.

\section{Method}

The method used was that of a prospective cohort study with a quantitative approach, carried out in a reference service in a city in upstate Paraíba, for the treatment of children and teenager who are overweight. A study was made on a sample by convenience, consisting of 109 children and adolescents who are obese or overweight, aged between 3 and 19, users of the Simple Health System, registered at the COI in Campina Grande, State of Paraíba, Brazil.

The present study makes an appraisal of the monitoring of the children and adolescents served by the COI. All the participants were accepted in the treatment as proposed in the first half of 2009. The data presented in this article were collected between April 2010 and April 2011. The sample was divided into two groups, according to the time in which they dropped out of specialised treatment, considering their last appointment, with the following configuration: groups with less than six months and group with more than six months away from the treatment. It is worth stressing that the participants continued being seen to through to the age of 19 or until they withdrew from the treatment.

The collection of data for the current research was made by the nurses at the COI, who got in touch with the patients by telephone and scheduled an assessment appointment on the COI premises, in a reserved room. At that time, the children or teenagers went with their parents or guardians who signed the authorisation and were present throughout the appraisal period. A checklist was then completed, to check if they: have been monitored continuously by the COI for at least 12 months since 2009; come to at least one appointment with each of the following professionals: nutritionist, endocrinologist and physical trainer; and have not used any medication which could affect their appetite and/ or their profile regarding blood fat and sugar. After this list has been answered and once the criteria for inclusion have been met, the patients were subjected to a measurement of anthropometric parameters and also application of a questionnaire which addressed demographic information and eating habits. In this last item, there were some objective questions about the frequency of each foodstuff on start of treatment in 2009, and in the present period, after at least 12 months of treatment. It must also be stressed that, when necessary, the people responsible for the children and teenagers helped with the answers.

To assess food frequency, the foodstuffs were put into two groups, according to the potential risk of cardiovascular disease. The foodstuffs classified as highrisk were: full-fat dairy products, animal fat, margarines (due to the content of trans fatty acids), fried foods, pasta, eggs, meat and derived products. The foodstuffs considered as protectors were: fruit and natural fruit juices, greens, vegetables, cereals and derived products $^{(10)}$.

Starting out from this point, we checked the answers given by the patients using the food frequency on entrance to be seen to at the COI and also after at least one year. Afterwards, a comparison was made, and then a classification of progress was established as improvement, worsening or stability, using as references the daily portions recommended by the Surveillance of Risk and Protection Factors for Chronic Diseases by Telephone Contact - VIGITEL 2009(11).

The data was analysed through the computer programme Statistical Package for the Social Sciences 
$\left(\mathrm{SPSS}^{\circledR}\right.$ ) for Windows, release 17.0 . To establish relationships between changes in eating habits and dropout times, the Chi-Square test was performed, considering a confidence interval of $95 \%$. The variables related to consumption (soft drinks, cold cuts, pasta, sweet goodies, sweets and vegetables), for which $p$ was less than $<0.2$, were then analysed using the model of logistic regression, to assess the influence of the control variables (age, sex and dropout period) on the consumption of such foodstuffs.

The study protocol was previously analysed and approved by the Research Ethics Committee of the State University of Paraíba under No. 0379.0.130.000-10, according to Resolution 196/96 passed by the Brazilian National Board of Health. The parents or guardians entered into the commitment through signing a Free and Informed Consent Form (ICF).

\section{Results}

Out of the 109 participants, 47 made up the group with more than 6 months away from the treatment, and 62 had been off the treatment for less than 6 months. In general, more than half $(67 \%)$ were female, and teenagers $(71.6 \%)$ with a family income of between 1 and 2 national minimum wages (39.4\%), of mixed colour $(67.9 \%)$ and with maternal schooling of more than 12 years $(49.5 \%)$. The specific characteristics of each group are described in Table 1.

As we can see in Table 2, on analysing the frequency with which the high-risk foods are ingested, we see that the patients who have been away from treatment for less than six months have shown improvement compared with the group that has been away from the treatment
Table 1 - Social and demographic characteristics of the groups monitored at the Infant Obesity Centre in Campina Grande, PB, Brazil, 2010-2011

\begin{tabular}{|c|c|c|c|c|c|c|}
\hline \multirow[t]{2}{*}{ Characteristics } & \multicolumn{2}{|c|}{$\begin{array}{c}\text { More than } 6 \\
\text { months off } \\
\text { treatment }\end{array}$} & \multicolumn{2}{|c|}{$\begin{array}{c}\text { Less than } 6 \\
\text { months off } \\
\text { treatment }\end{array}$} & \multicolumn{2}{|c|}{ Total } \\
\hline & $\mathbf{N}$ & $\%$ & $\mathbf{N}$ & $\%$ & $\mathbf{N}$ & $\%$ \\
\hline \multicolumn{7}{|l|}{ Sex } \\
\hline Female & 35 & 74,5 & 38 & 61,3 & 73 & 67 \\
\hline Male & 12 & 25,5 & 24 & 38,7 & 36 & 33 \\
\hline \multicolumn{7}{|l|}{ Age Group } \\
\hline Pre-school & 1 & 2,1 & 4 & 6,5 & 5 & 4,6 \\
\hline School & 7 & 14,9 & 19 & 30,6 & 26 & 23,8 \\
\hline Adolescents & 39 & 83 & 39 & 62,9 & 78 & 71,6 \\
\hline \multicolumn{7}{|l|}{ Family Income $\left(\mathrm{MW}^{*}\right)$} \\
\hline $1 / 4$ to $1 / 2$ & 2 & 4,3 & 5 & 8,1 & 7 & 6,4 \\
\hline $1 / 2$ to 1 & 7 & 14,9 & 13 & 21 & 20 & 18,3 \\
\hline 1 to 2 & 22 & 46,8 & 21 & 33,9 & 43 & 39,5 \\
\hline 2 to 5 & 15 & 31,9 & 19 & 30,6 & 34 & 31,2 \\
\hline$>5$ & 1 & 2,1 & 3 & 4,8 & 4 & 3,7 \\
\hline Not known & 0 & 0 & 1 & 1,6 & 1 & 0,9 \\
\hline \multicolumn{7}{|l|}{ Ethnicity } \\
\hline White & 14 & 29,8 & 13 & 21 & 27 & 24,8 \\
\hline Mixed & 29 & 61,7 & 45 & 72,6 & 74 & 67,9 \\
\hline Black & 4 & 8,5 & 3 & 4,8 & 7 & 6,4 \\
\hline Not known & 0 & 0 & 1 & 1,6 & 1 & 0,9 \\
\hline \multicolumn{7}{|l|}{ Schooling of Mother ${ }^{\dagger}$} \\
\hline 0 to 8 years & 14 & 29,8 & 21 & 33,9 & 35 & 32,1 \\
\hline 9 to 11 years & 9 & 19,1 & 11 & 17,7 & 20 & 18,3 \\
\hline 12 or more & 24 & 51,1 & 30 & 48,4 & 54 & 49,6 \\
\hline
\end{tabular}

*Minimum Wage

tIn years of schooling

for more than six months. The main foodstuffs that have shown evidence of this result were respectively, for groups with less and more than six months of dropout: soft drinks (61.3\% and $27.7 \%$ ), pasta (50\% and $34 \%$ ) and fried foods (46.8\% and $36.2 \%$ ).

Table 2 - Frequency of ingestion of high-risk food in the groups monitored by the Infant Obesity Centre in Campina Grande, PB, Brazil, 2010-2011

\begin{tabular}{|c|c|c|c|c|c|c|c|c|c|}
\hline \multirow{2}{*}{ Foodstuffs } & \multicolumn{3}{|c|}{ More than 6 months of dropout } & \multicolumn{3}{|c|}{ Less than 6 months of dropout } & \multicolumn{3}{|c|}{ Total } \\
\hline & $\mathrm{PI} \%$ & ME\% & MA\% & $\mathrm{PI} \%$ & ME\% & MA\% & $\mathrm{PI} \%$ & ME\% & MA\% \\
\hline Fried Foods & 42.6 & 36.2 & 21.3 & 29.0 & 46.8 & 24.2 & 34.9 & 42.2 & 22.9 \\
\hline Cold Cuts & 21.3 & 19.1 & 59.6 & 9.7 & 33.9 & 56.5 & 14.7 & 27.5 & 57.8 \\
\hline Sweets/Chocolate & 29.8 & 21.3 & 48.9 & 29.0 & 43.5 & 27.4 & 29.4 & 33.9 & 36.7 \\
\hline Confectionery & 38.3 & 25.5 & 36.2 & 16.1 & 40.3 & 43.5 & 25.7 & 33.9 & 40.4 \\
\hline Biscuits & 40.4 & 34.0 & 25.5 & 48.4 & 33.9 & 17.7 & 45 & 33.9 & 21.1 \\
\hline Soft Drinks & 31.9 & 27.7 & 40.4 & 17.7 & 61.3 & 21.0 & 23.9 & 46.8 & 29.4 \\
\hline Pasta & 36.2 & 34.0 & 29.8 & 22.6 & 50.0 & 27.4 & 28.4 & 43.1 & 28.4 \\
\hline
\end{tabular}

$\mathrm{PI}=$ percentage of worsening; $\mathrm{ME}=$ percentage of improvement; $\mathrm{MA}=$ percentage of maintenance 
In Table 3, concerning the protector foods, we see that the individual subjects have started to consume more fruit (30.3\%) and vegetables (26.6\%) in the total sample. These same foodstuffs have had greater intake among the patients who have been dropped out from monitoring for less than six months, with observation of $32.3 \%$ for fruit, compared with $27.7 \%$ in the case of the group more than six months away from treatment. In relation to vegetables, there was a consumption rate of $32.3 \%$ and $19.1 \%$ among the participants with less and more dropout time, respectively.

Table 3 - Frequency of ingestion of protector food in the groups monitored by the Infant Obesity Centre in Campina Grande, PB, Brazil, 2010-2011

\begin{tabular}{|c|c|c|c|c|c|c|c|c|c|}
\hline \multirow{2}{*}{ Foodstuffs } & \multicolumn{3}{|c|}{ More than 6 months of dropout } & \multicolumn{3}{|c|}{ Less than 6 months of dropout } & \multicolumn{3}{|c|}{ Total } \\
\hline & $\mathrm{PI} \%$ & ME\% & MA\% & $\mathrm{PI} \%$ & ME\% & MA\% & $\mathrm{PI} \%$ & ME\% & MA\% \\
\hline Beans & 25.5 & 14.9 & 59.6 & 14.5 & 12.9 & 72.6 & 19.3 & 13.8 & 67 \\
\hline Fruit & 34.0 & 27.7 & 38.3 & 25.8 & 32.3 & 41.9 & 29.4 & 30.3 & 40.4 \\
\hline Vegetables & 57.4 & 19.1 & 23.4 & 43.5 & 32.3 & 24.2 & 49.5 & 26.6 & 23.9 \\
\hline Milk & 51.1 & 6.4 & 42.6 & 48.4 & 8.1 & 43.5 & 49.5 & 7.3 & 43.1 \\
\hline Yoghurt & 55.3 & 14.9 & 29.8 & 61.3 & 9.7 & 29.0 & 58.7 & 11.9 & 29.4 \\
\hline Cheese & 51.1 & 19.1 & 29.8 & 59.7 & 11.3 & 29.0 & 56 & 14.7 & 29.4 \\
\hline
\end{tabular}

$\mathrm{PI}=$ percentage of worsening; $\mathrm{ME}=$ percentage of improvement; $\mathrm{MA}=$ percentage of maintenance

On comparing the two groups, we have seen that the values show an association between the patients with less than six months away from the monitoring process and improvement in the consumption of soft drinks and sweets/chocolate $(p=0.000$ and $p=0.015$, respectively), as shown in Table 4.

Table 4 - Frequency, significance, prevalence ratio and confidence interval for food consumption frequency among children and teenagers registered at the Infant Obesity Centre, in the city of Campina Grande, PB, Brazil, between 2010 and 2011

\begin{tabular}{|c|c|c|c|c|}
\hline \multirow[b]{2}{*}{ Variables } & \multicolumn{2}{|c|}{ Dropout Period } & \multirow[b]{2}{*}{ RP (IC - 95\%) } & \multirow[b]{2}{*}{$p$} \\
\hline & $\begin{array}{c}>6 \\
\text { months }\end{array}$ & $\begin{array}{c}<6 \\
\text { months }\end{array}$ & & \\
\hline \multicolumn{5}{|l|}{ Beans } \\
\hline Worse or the same & 85.1 & 87.1 & $1.18(0.39-3.52)$ & 0.765 \\
\hline Improved & 14.9 & 12.9 & & \\
\hline \multicolumn{5}{|l|}{ Fruit } \\
\hline Worse or the same & 72.3 & 67.7 & $0.81(0.34-1.84)$ & 0.605 \\
\hline Improved & 27.7 & 32.3 & & \\
\hline \multicolumn{5}{|l|}{ Vegetables } \\
\hline Worse or the same & 80.9 & 67.7 & $0.49(0.20-1.22)$ & 0.125 \\
\hline Improved & 19.1 & 32.3 & & \\
\hline \multicolumn{5}{|l|}{ Milk } \\
\hline Worse or the same & 93.6 & 91.9 & $0.77(0.17-3.43)$ & 0.739 \\
\hline Improved & 6.4 & 8.1 & & \\
\hline \multicolumn{5}{|l|}{ Yoghurt } \\
\hline Worse or the same & 85.1 & 90.3 & $1.63(0.51-5.22)$ & 0.405 \\
\hline Improved & 14.9 & 9.7 & & \\
\hline
\end{tabular}

Table 4 - (continuation)

\begin{tabular}{|c|c|c|c|c|}
\hline \multirow[b]{2}{*}{ Variables } & \multicolumn{2}{|c|}{ Dropout Period } & \multirow[b]{2}{*}{ RP (IC - 95\%) } & \multirow[b]{2}{*}{$p$} \\
\hline & $\begin{array}{c}>6 \\
\text { months }\end{array}$ & $\begin{array}{c}<6 \\
\text { months }\end{array}$ & & \\
\hline \multicolumn{5}{|l|}{ Cheese } \\
\hline Worse or the same & 80.9 & 88.7 & $1.86(0.63-5.42)$ & 0.251 \\
\hline Improved & 19.1 & 11.3 & & \\
\hline \multicolumn{5}{|l|}{ Fried Foods } \\
\hline Worse or the same & 63.8 & 53.2 & $0.64(0.29-1.4)$ & 0.267 \\
\hline Improved & 36.2 & 46.8 & & \\
\hline \multicolumn{5}{|l|}{ Processed Meats } \\
\hline Worse or the same & 80.9 & 66.1 & $0.46(0.18-1.13)$ & 0.088 \\
\hline Improved & 19.1 & 33.9 & & \\
\hline \multicolumn{5}{|l|}{ Biscuits } \\
\hline Worse or the same & 66.0 & 66.1 & $1.01(0.45-2.24)$ & 0.985 \\
\hline Improved & 34.0 & 33.9 & & \\
\hline \multicolumn{5}{|l|}{ Sweets/Chocolate } \\
\hline Worse or the same & 78.7 & 56.5 & $0.35(0.14-0.82)$ & 0.015 \\
\hline Improved & 21.3 & 43.5 & & \\
\hline \multicolumn{5}{|l|}{ Confectionery } \\
\hline Worse or the same & 74.5 & 59.7 & $0.51(0.22-1.16)$ & 0.106 \\
\hline Improved & 25.5 & 40.3 & & \\
\hline \multicolumn{5}{|l|}{ Soft Drinks } \\
\hline Worse or the same & 72.3 & 38.7 & $0.24(0.11-0.54)$ & 0.000 \\
\hline Improved & 27.7 & 61.3 & & \\
\hline \multicolumn{5}{|l|}{ Pasta } \\
\hline Worse or the same & 66.0 & 50.0 & $0.51(0.23-1.12)$ & 0.095 \\
\hline Improved & 34.0 & 50.0 & & \\
\hline
\end{tabular}

On carrying out logistic regression, it was observed that vegetables and confectionery did not get a variable 
in the final model, while soft drinks and goodies are related to sex, and processed meats and pasta to the age bracket. In the case of processed meats, the time of service variable did not enter (Table 5).

Table 5 - Logistic regression of food ingestion frequency related to time of service, sex and age bracket of children and teenagers registered at the Infant Obesity Centre in the city of Campina Grande, PB, Brazil, 2010-2011

\begin{tabular}{lcc}
\hline Foodstuffs and Variables & OR (IC-95\%) & p \\
\hline Soft Drinks & & \\
$\quad$ Service Time & $3.5(1.55-8.31)$ & 0.039 \\
Age & $0.37(0.14-0.92)$ & 0.034 \\
Processed Meats & & \\
Sex & $3.37(1.4-8.1)$ & 0.007 \\
Pasta & & \\
Service Time & $2.34(1.02-5.34)$ & 0.004 \\
$\quad$ Sex & $0.31(0.13-0.78)$ & 0.012 \\
Goodies & & \\
$\quad$ Service Time & $2.85(1.20-6.74)$ & 0.017 \\
\hline
\end{tabular}

In relation to monitoring time, we observed that the patients who had been more than six months away from the treatment had a risk 3.5 times as large of increasing their consumption of soft drinks, 2.34 times for pasta and 2.85 times for goodies.

In the case of sex, girls had a probability 3.37 times as high of getting worse in terms of consumption of processed meats. However, in the case of pasta consumption they improved 3.2 times as much as boys did. In relation to age bracket, only the consumption of soft drinks was worse, over one year, for teenagers $(\mathrm{OR}=0,37)$.

\section{Discussion}

In the present study, the participants were children and adolescents who were overweight and who were served by a reference centre. Obesity in this age bracket tends to persist into adulthood and is also associated to the onset of cardiovascular and metabolic disorders ${ }^{(12)}$.

On comparing food frequency between the groups in this research study, it was observed that the patients with less time from the last appointment got better results, mainly in relation to a reduction in the intake of risky foods (soft drinks, pasta and fried foods) and a better consumption of fruit and vegetables. The results of the study performed in a public service company for obese teenagers in Minas Gerais confirmed the findings of the present study, as it was observed that the patients monitored had an increase in the intake of healthy foods and a reduction of high-calorie foods ${ }^{(13)}$. Thus, the target population, when monitored by a reference service and with less time away from the treatment, manages to understand the disadvantages of the risk foods and the benefits of protector foods, adapting them to their diet.

The results as here described also suggest that the subjects who had been longest away from the treatment had a tendency to increase their consumption of soft drinks, pasta and goodies. About this point, many are the factors which seem to interfere with food consumption in this age bracket, including social and cultural image, body image, social group, family income, eating outside the home, increased consumption of highenergy foods, the influence of the media and coexisting group, skipping meals, and the distance between home and school, availability and easy preparation of food, as well as mood swings( ${ }^{(2)}$. However, this adverse scenario can be modified with professional help, stressing education within the family nucleus, preferably with multiprofessional monitoring(13).

Considering the differences between the sexes, we see that girls were much more likely to get worse regarding consumption of processed meats and improve regarding consumption of pasta. This result matches the findings of a study which appraised the eating habits of young people at University, which came to the conclusion that the food habits of girls showed unsuitability to the consumption of processed meats, reflecting a preference for lighter meals at lunch time or diner time, which was normally avoided among males, who preferred consumption of denser food such as pasta. Thus, men and women have different eating habits, suggesting the need for a different approach and also the drawing up of strategies for promotion of health that are suitable for each $\operatorname{sex}^{(14)}$.

The finding that teenagers drink more soft drinks, when compared to children, could be related to the greater freedom for teenagers to buy these foods ${ }^{(8)}$. A study of consumption of soft drinks among school pupils at state schools in the city of Niterói, State of Rio de Janeiro, shows that this was higher in older students, while the consumption of milk was more widespread among younger students. It was therefore shown that there was a trend to replace milk by soft drinks as age increased, which shows an unhealthy practice and which can be reversed due to intervention and health education at our schools ${ }^{(15)}$. 
In addition, a systematic review of the specialised literature has reached the conclusion that, to understand the frequent consumption of sugar-laden foods by teenagers, one must consider the marketing aspect. Indeed, sugar is one of the most important items within a wide range of unhealthy foods that often mine educational strategies and behaviour modification, especially among the young(16). A study conducted in Poland, with 1,829 children and teenagers aged between 10 and 15, showed that most of them consumed confectionery to excess, which could have a negative impact on their development and also on their health(17).

Despite the identification of a greater risk for inappropriate food ingestion frequency among some participants, it was observed that multidisciplinary monitoring has contributed to improve such frequencies, especially among those in the group and less than six months from the last appointment. Based on this improvement of nutritional quality, it has been possible to identify that multiprofessional service has had a positive result. About this point, it is important to stress that the encouragement to programmes of food guidance could bring about the development of an appropriate nutritional state. The promotion and maintenance of these habits within this age bracket will lead to healthier adults who have a lower risk of chronic non-contagious diseases $^{(18)}$.

For these reasons, in order to avoid complications in the general health conditions of the teenagers who are overweight or obese, the nursing division is a kind of mediator between the health service and the family. In this perspective, a study of the review has said that the following types of nursing intervention are essential: guidance about children's nutrition; build awareness in the parents about the importance of prevention of infant obesity with lectures, educational leaflets and house visits; inform the family about pathology, including its causes and consequences; nutritional monitoring of the children; pay attention to improvement of eating habits, showing more appropriate menus, setting times and places; encouragement of physical exercise, play activities and sporting games; assess the psychic and social state of the child and the family; show that healthy food is not any more expensive; analyse to see if there is any appearance of an opportunistic disease amid obesity; and also give guidance about need for medical monitoring of those children who have already reached a more advanced stage of the disease ${ }^{(19)}$.

Among this intervention, psychological support is important, as obese children and teenagers face social discrimination. A study held in the Mexican city of Tamaulipas, with 24 obese teenagers, said that they had low self-esteem, difficulty to indulge in physical activities, and also difficulty to buy clothes to improve their own image, not to mention prejudice and rejection from the other adolescents ${ }^{(18)}$.

With guidance and monitoring, the trend now is that children and teenagers shall change their life habits (diet and physical exercise), even if they are not able to carry out all the instructions. Here I stress that it is very important to give praise, even for the smallest changes, such as changing a tasty salty snack for fruit while at school, to encourage them to improve. This treatment is a long process, and the prevention of metabolic disturbances is a priority in public health. The change can even start during the nursing appointments at the basic health units ${ }^{(19)}$.

Here we highlight that the assessment based on the personal report on food frequency of overweight children and adolescents is considered a limiting factor for this study as, according to specialised literature as here consulted, there is evidence of underreporting of food frequencies among overweight individuals ${ }^{(3)}$. However, we praise the importance of this study, due to its contribution of recent data to the national scene, in relation to the monitoring of patients in the reference centre for the treatment of overweight children and adolescents, as most of the surveys published address only part of this population (either children or adolescents). In addition, the fact that the monitoring has been spread over one year confirms the value of the investigation.

Finally, we mention that a study carried out in Mexico about the obesity issue in children or adolescents discussed, with a qualitative approach, the psychological aspects that interfere with the social relationships of young obese people, and the need for nursing interventions that are specific for this population ${ }^{(18)}$. The study as presented here is an advancement of scientific knowledge, on analysing if the specialised and multiprofessional monitoring may contribute towards the modification of food frequency and, hence, has the potential to improve the general health conditions of children and teenagers who are obese.

\section{Conclusion}

Some of the children and adolescents with excess weight included in this study were still consuming risk foods, but as a whole the multidisciplinary monitoring brought positive results, as generally the participants 
decided to understand the importance of avoiding risk foods and increasing the consumption of protector foods.

We must also stress that the food situation of this population is still a cause for concern, as there is a need for these changed habits to remain, in order to avoid cardiac and metabolic diseases. This difficulty was observed mainly in the groups with greatest time away from the treatment, showing that one of the major challenges is that of keeping the children and the teenagers under accompaniment. This means a need to draw up strategies that reinforce educational actions, including a debate about policies and programmes that may rescue cultural distortions, to encourage the general population to join up with healthy practices, thus avoiding obesity and its comorbidities.

Considering the main results, the main contribution of this study is that of showing that multiprofessional monitoring is indeed efficient for changing the food frequency of children with excess weight. Thus, considering the nurse as part of the team, we see that excess weight in children and adolescents shall be assessed with care during the nursing appointment, in order to offer the best possible guidance and identify those individuals with the highest risk of metabolic alterations to send them on to a reference service. For this, we stress the need for training of the nurses, aimed at the identification and the accompaniment of overweight right from infancy, as this is associated with an adverse metabolic profile.

\section{References}

1. Rodrigues EM, Boog MCF. Problematização como estratégia de educação nutricional com adolescentes obesos. Cad Saúde Pública. maio 2009; 22(5): 923-31.

2. Dishchekenian VRM, Escrivão MAMS, Palma D, Ancona-Lopez F, Araújo EAC, Taddei JAAC, et al. Padrões alimentares de adolescentes obesos e diferentes repercussões metabólicas. Rev Nutr. jan/feb 2011;24(1):17-29.

3. Salvatti AG, Escrivão MAMS, Tadei JAAC, Bracco MM. Padrões alimentares de adolescentes na cidade de São Paulo. Rev Nutr. sept-oct 2011;24(5):703-13.

4. McNaughton SA, Ball K, Mishra GD, Crawford DA. Dietary patterns of adolescents and risk of obesity and hypertension. J Nutrition. [periódico na Internet]. 2008 [acesso 5 jun 2012]; 138:364-70. Disponível em: http://jn.nutrition.org/content/138/2/ 364.full.pdf+html
5. Mariz LS, Azevedo LB, Medeiros CCM, Gonzaga NC, Amorim SD, Souza LCF. Centro de obesidade infantil: relato de experiência. Cogitare Enferm. [periódico na Internet] abr-jun 2012 [acesso 20 abril 2013; 17(2):369-72. Disponível em: http://ojs.c3sl.ufpr.br/ ojs2/index.php/cogitare/article/view/27900/18557

6. Brasil. Ministério da Saúde. Saúde da Criança: Acompanhamento do Crescimento e Desenvolvimento Infantil. Brasília: Ministério da Saúde; 2002.

7. Cattai BP, Rocha FAR, Hintze LJ, Pagan BGM, Nardo $\mathrm{N}$ Júnior. Programa de tratamento multiprofissional da obesidade: os desafios da prática. Ciênc Cuid Saúde. 2008;7(suppl.1):121-6.

8. Silveira AM, Jansen AK, Norton RC, Silva GSE, Whyte PPM. Efeito do atendimento multidisciplinar na modificação dos hábitos alimentares e antropometria de crianças e adolescentes com excesso de peso. Rev Méd Minas Gerais. jul-set 2010;20(3):277-84.

9. Ministério da Saúde (BR). Agenda Nacional de Prioridades de Pesquisa em Saúde. 2. ed. Série B. Textos Básicos em Saúde. Brasília: Ministério da Saúde; 2009. 10. Fornés NS, Martins IS, Velásquez-Meléndez G, Latorre MRDO. Escores de consumo alimentar e níveis lipêmicos em população de São Paulo, Brasil. Rev Saúde Pública. 2002;36(1):12-8.

11. Ministério da Saúde (BR). Vigitel Brasil 2009: vigilância de fatores de risco e proteção para doenças crônicas por inquérito telefônico. Ministério da Saúde, Secretaria de Vigilância em Saúde, Secretaria de Gestão Estratégica e Participativa. Brasília: Ministério da Saúde; 2010.

12. Rico RC, Rico RG, Almeida CAN, Ramos APP. Estudo comparativo de fatores de risco em crianças e adolescentes com diagnóstico antropométrico de sobrepeso ou obesidade. Rev Paul Pediatria. [periódico na Internet] 2010 [acesso 5 jun 2012]; 28(4):320-5. Disponível em: http://www.scielo.br/pdf/rpp/v28n4/ a06v28n4.pdf

13. Oliveira TRPR, Cunha CF, Ferreira RA. Educação nutricional como estratégia de intervenção para o tratamento da obesidade na adolescência. Rev Méd Minas Gerais. 2008;18(suppl.3):67-75.

14. Feitosa EPS, Dantas CAO, Andrade-Wartha ERS, Marcellini PS, Mendes-Netto RS. Hábitos alimentares de estudantes de uma universidade pública do Nordeste. Alim Nutr. 2010;21(2):225-30.

15. Nogueira FAM, Sichieri R. Associação entre consumo de refrigerantes, sucos e leite, com o índice de massa corporal em escolares da rede pública de Niterói, Rio de Janeiro, Brasil. Cad Saúde Pública. dez 2009;25(12):2715-24. 
16. Sichieri R, Souza RA. Estratégias para prevenção da obesidade em crianças e adolescentes. Cad Saúde Pública. 2008;24 Suppl 2:209-34.

17. Dietetyki Z, Klinicznego Z. Selected nutritional habits children and teenagers aged 10-15 years. Rocz Panstw Zakl Hig. [journal on the Internet] 2012 [acesso 20 abril 2013]; 63(1):91-7. Disponível em: http://www.ncbi. nlm.nih.gov/pubmed/22642075/

18. Martínez-Aguilar ML, Flores-Peña Y, Rizo-Baeza MM, Aguilar-Hernández RM, Vázquez-Galindo L, GutiérresSánchez G. 7th to 9th Grade Obese Adolescents' Perceptions About Obesity in Tamaulipas, Mexico. Rev. Latino-Am. Enfermagem. 2010 Jan/Feb;18(1):48-53.

19. Fernandes RA, Vargas SA. O cuidado de enfermagem na obesidade infantil. Rev Meio Amb Saúde. $2008 ; 2(1): 273-81$. 